\title{
Glycoprotein Hormones Alpha Polypeptide
}

National Cancer Institute

\section{Source}

National Cancer Institute. Glycoprotein Hormones Alpha Polypeptide. NCI Thesaurus. Code C65745.

The alpha polypeptide chain of any of the four human glycoprotein hormones chorionic gonadotropin (CG), luteinizing hormone (LH), follicle-stimulating hormone (FSH), and thyroid-stimulating hormone (TSH). Overexpressed in certain estrogen receptor (ER)positive cancers, glycoprotein hormones alpha polypeptide (choriogonadotropin alpha; CGA) may be used as a biomarker for these types of cancer or as a predictor for the responsiveness of certain anti-estrogen therapy. 